\title{
Differences and characteristics of symptoms by tumor location, size, and degree of spinal cord compression: a retrospective study on 53 surgically treated, symptomatic spinal meningiomas
}

\author{
Satoshi Yamaguchi, MD, ${ }^{1}$ Arnold H. Menezes, MD, ${ }^{1}$ Kiyoharu Shimizu, MD, ${ }^{2}$ \\ Royce W. Woodroffe, MD, ${ }^{1}$ Logan C. Helland, MD, ${ }^{1}$ Patrick W. Hitchon, MD, ${ }^{1}$ and \\ Matthew A. Howard III, MD'1
}

'Department of Neurosurgery, University of lowa Hospitals and Clinics, lowa City, lowa; and 'Department of Neurosurgery, Graduate School of Biomedical and Health Sciences, Hiroshima University, Hiroshima, Japan

\begin{abstract}
OBJECTIVE The differences in symptoms of spinal meningiomas have rarely been discussed from the perspective of tumor characteristics. The main purpose of this paper was to define the differences, if any, in symptoms in patients with spinal meningiomas with respect to tumor size, location, and degree of spinal cord compression. The authors also sought the threshold of spinal cord compression that causes motor weakness.
\end{abstract}

METHODS The authors conducted a retrospective study of 53 cases of spinal meningiomas that were surgically treated from 2013 to 2018. Symptoms related to the tumor were classified as motor weakness, sensory disturbance, pain, and bowel/bladder dysfunction. Based on MR images, tumor location was classified by spinal level and by its attachment to the dura mater. Tumor dimensions were also measured. Occupation ratios of the tumors to the spinal canal and degree of spinal cord flattening were sought from the axial MR images that showed the highest degree of spinal cord compression.

RESULTS Motor weakness and sensory disturbance were significantly more common in thoracic spine meningiomas than in cervical spine meningiomas ( $p<0.001$ and $p=0.013$, respectively), while pain was more common in meningiomas at the craniovertebral junction $(p<0.001)$. The attachment, height, width, depth, and volume of the tumor showed no significant difference irrespective of the presence or absence of each symptom. In cases of motor weakness and sensory disturbance, occupation ratios and spinal cord flattening ratios were significantly larger. However, these ratios were significantly smaller in the presence of pain. Multivariate logistic regression analysis revealed that occupation ratio independently contributed to motor weakness (OR 1.14, $p=0.035)$ and pain (OR 0.925, $p=0.034)$. Receiver operating characteristic curve analysis suggested that occupation ratio with a value of $63.678 \%$ is the threshold for the tumor to cause motor weakness.

CONCLUSIONS The study showed the difference in clinical presentation of spinal meningiomas by spinal level, occupation ratio, and spinal cord flattening ratio. An occupation ratio of approximately $64 \%$ could be utilized as the threshold value of tumor growth to cause motor weakness. Tumor growth in the cervical spine might cause pain symptoms before causing motor weakness. The relationship between the tumor and its symptomatology should be discussed with respect to tumor size relative to the surrounding spinal canal.

https://thejns.org/doi/abs/10.3171/2019.12.SPINE191237

KEYWORDS spinal meningioma; spinal level; tumor dimension; occupation ratio; oncology

$\mathrm{S}$ PINAL meningiomas are one of the most common intraspinal neoplasms and account for $24.4 \%-36 \%$ of primary spinal intradural tumors. ${ }^{4,5,21,29}$ Large epidemiological studies from the United States have revealed that the overall age-adjusted incidence of spinal menin- giomas is $0.19-0.35$ per 100,000 population, ${ }^{4,15,29}$ with the mean patient age ranging from 49 to 54 years. ${ }^{7,10,16}$ Female patients account for $75 \%-85 \%$ of all patients. The reason for female preponderance is speculated to be the dependence of tumor growth on sex hormones. ${ }^{5,7,9,10,15,16,25,29}$ As

ABBREVIATIONS BBD = bowel/bladder dysfunction; $C V J=$ craniovertebral junction; OPLL = ossification of the posterior longitudinal ligament .

SUBMITTED October 16, 2019. ACCEPTED December 2, 2019.

INCLUDE WHEN CITING Published online January 31, 2020; DOI: 10.3171/2019.12.SPINE191237. 
for spinal level, $55 \%-83 \%$ of spinal meningiomas affect the thoracic spine. Approximately 15\% of the tumors are found in the cervical spine. The lumbar spine is the least affected site, with a frequency of only $2 \% .2,7,8,16,25$ More than $95 \%$ of spinal meningiomas are classified as benign or WHO grade I, while less than $2 \%$ of meningiomas are classified as grade II or III. ${ }^{10,15,21,29}$ The slow-growing nature of the tumor contributes to a longer duration of symptoms before diagnosis and treatment. The mean duration of symptoms in the literature ranges from 6 to 23 months..$^{10,16 \text {, }}$ $18,23,25$ Symptoms are generally due to compression of the spinal cord and/or nerve roots, simply described as sensory disturbance, motor weakness, bowel/bladder dysfunction (BBD), and pain. ${ }^{2,3,7,9,19,23}$ The differences and characteristics of the symptoms have rarely been studied from the perspective of spinal level and tumor size., ${ }^{3,22}$ The threshold of spinal cord compression that leads to the onset of neurological symptoms has never been sought before. In this paper, we retrospectively reviewed 53 cases of surgically treated spinal meningiomas to find an association of symptoms with the location and size of the tumor. The symptomatology of spinal meningiomas will be reviewed.

\section{Methods}

This study was approved by our institutional review board. We conducted a retrospective study on spinal meningiomas 1) to see if there was any difference in frequency of symptoms depending on the location and size of the tumor; 2) to see if there was any difference in tumor dimensions and the degree of the spinal cord compression between the presence and absence of certain symptoms; 3) to identify contributing factors for the symptoms; and 4) to determine the critical size of the tumor for presentation of neurological symptoms. From January 2013 to December 2018, we identified 63 surgical cases of spinal meningiomas at the Department of Neurosurgery, University of Iowa Hospitals and Clinics. Among 63 cases, 7 cases of asymptomatic meningiomas were excluded. Two cases of meningiomas in the lumbar spine and 1 case of an extradural meningioma were excluded because of an absence of mass effect on the spinal cord. Thus, 53 meningiomas in 53 patients were reviewed for statistical analysis. The electronic medical records and preoperative MR images were sought to obtain the following data, in addition to the following basic information of the patients:

- WHO grade: grade I, II, or III;

- Spinal level of tumor attachment: craniovertebral junction (CVJ; foramen magnum to $\mathrm{C} 2$ ), subaxial cervical spine (C3-7), and thoracic spine (T1-12);

- Clinical symptoms: motor weakness, sensory disturbance, pain, and BBD;

- Tumor dimensions: height, width, and depth (mm) (Fig. 1a and b);

- The attachment of the tumor in the spinal canal (Fig. 2);

- Estimated tumor volume: ${ }^{6}$ volume $\left(\mathrm{mm}^{3}\right)=(\pi \times$ height $\times$ width $\times$ depth $) / 6$;

- Cross-sectional area $\left(\mathrm{mm}^{2}\right)$ of the spinal canal and that of the tumor measured on the axial T1-weighted contrast-enhanced MR image that showed the highest degree of spinal cord compression;
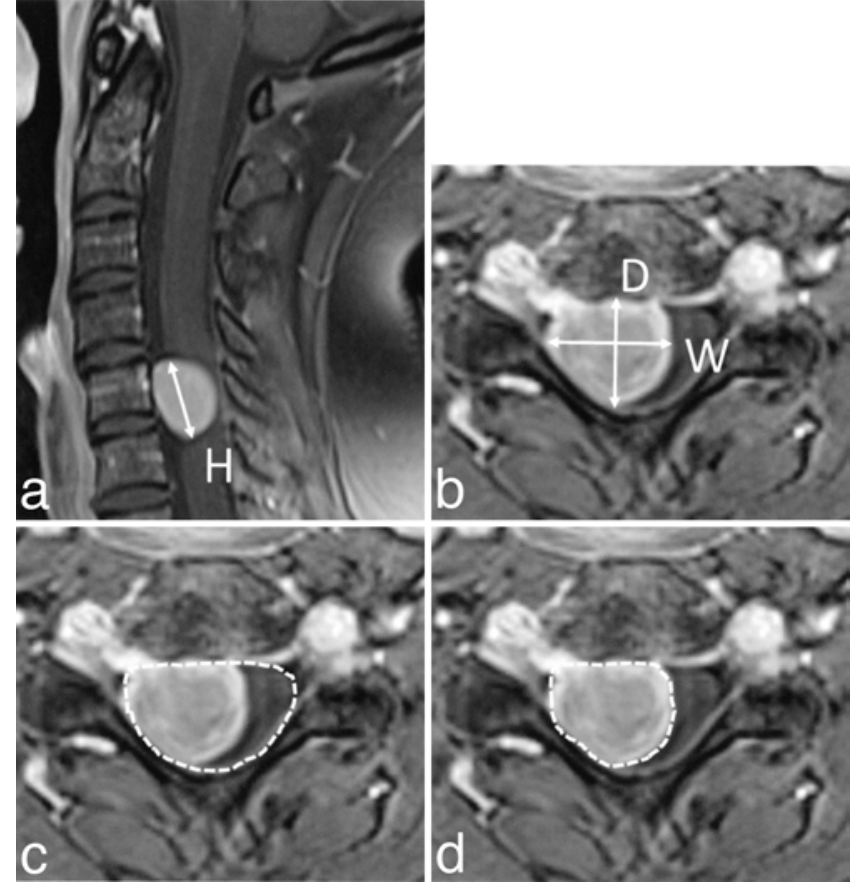

FIG. 1. Images demonstrating how the tumor dimensions were measured in this study. All measurements were made based on contrastenhanced T1-weighted MR images. a and b: Height $(H)$ was measured on sagittal images. Width (W) and depth (D) were measured on axial images. All measurements were recorded in millimeters. $c$ and $\mathrm{d}$ : Cross-sectional area $\left(\mathrm{mm}^{2}\right)$ of the spinal canal (c) and that of the tumor (d) were measured on axial images, which showed the highest degree of spinal cord compression. Occupation ratios (\%) were then sought from these values.

- Occupation ratio of the tumor in the spinal canal: occupation ratio $(\%)=$ tumor area $\left(\mathrm{mm}^{2}\right) /$ spinal canal area $\left(\mathrm{mm}^{2}\right) \times 100$ (Fig. 1c and d);

- The degree of spinal cord flattening by tumor was sought by the following formula based on axial T2weighted MR images: ${ }^{3}$ spinal cord flattening ratio (\%) $=100-$ (area of spinal cord at maximum compression/ [area of cord above + area of cord below]/2) $\times 100$.

Measurements were taken using a picture archiving communication system (version 12.1.6.1005, Carestream Vue PACS Carestream Health) by a single author (S.Y.). Patients were then classified according to the presence or absence of motor weakness, sensory disturbance, pain, and BBD. Patients with motor weakness were further classified as follows: 1) subjective motor weakness: patients complaining of difficulty walking and/or hand clumsiness but still preserving grade 5 muscle strength in all extremities; and 2) objective motor weakness: muscle strength $\leq$ grade 4 seen in at least 1 extremity. Sensory disturbance included numbness, tingling, and decreased sensation. Pain symptoms included radicular-type pain and local pain along the spinal axis. Occipitalgia was also classified in this category in cases of CVJ meningiomas.

\section{Statistical Analysis}

Statistical analysis was performed using Easy R (Saita- 

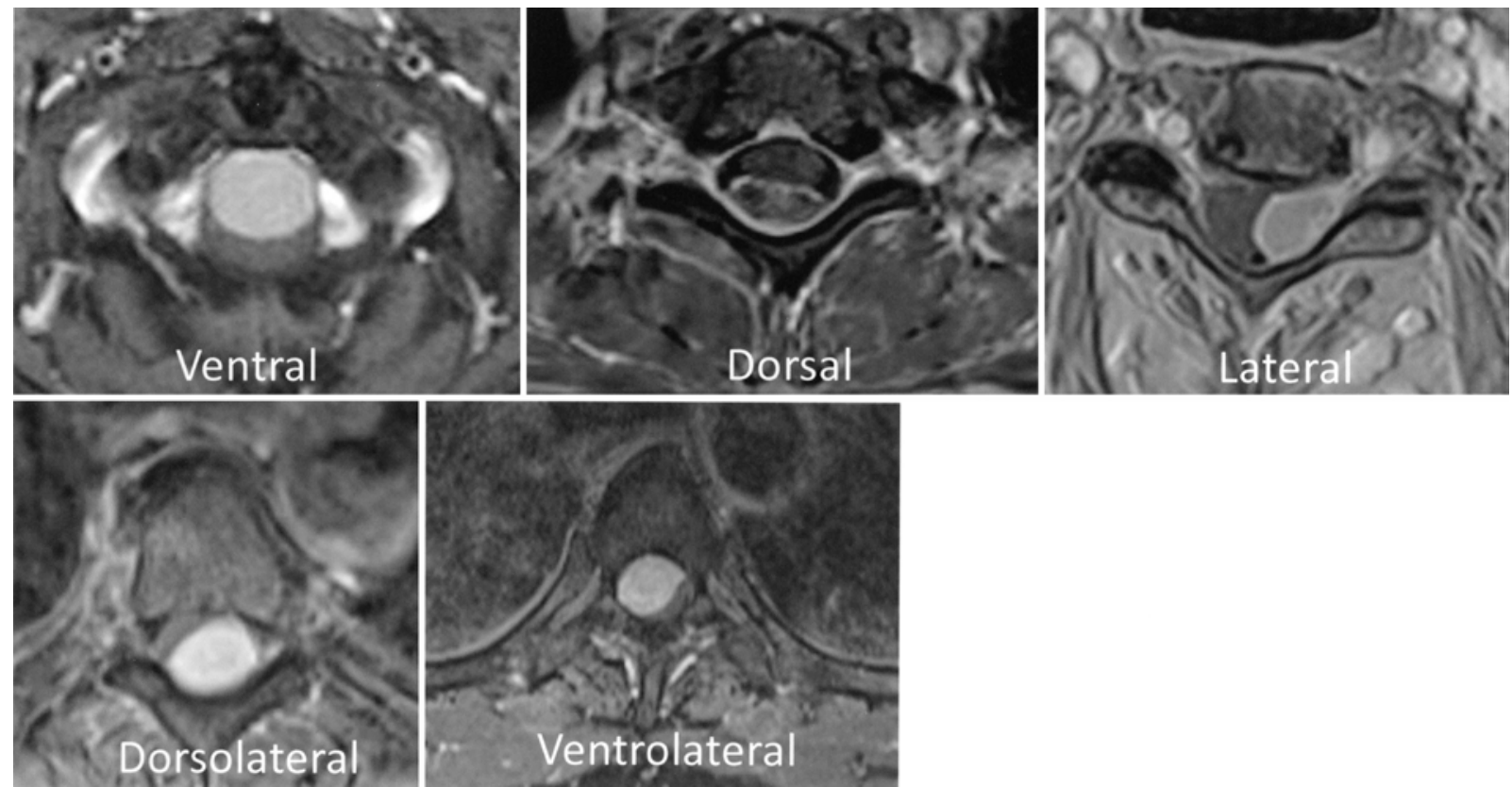

FIG. 2. The classification of the attachment of the tumor. The type of attachments was classified into ventral, dorsal, lateral, dorsolateral, and ventrolateral, depending on the location of the tumor and the direction of the deviation of the spinal cord.

ma Medical Center, Jichi Medical University), a graphical user interface for R (The R Foundation for Statistical Computing) $\cdot{ }^{13}$ Fisher's exact test was applied to see if there was a nonrandom association between two categorical variances. To compare continuous variables among 2 and 3 groups, the Mann-Whitney U-test and Kruskal-Wallis test were used, respectively. When the Kruskal-Wallis test showed a significant difference, the Mann-Whitney U-test was used for pairwise comparison. The $p$ values were then adjusted by Bonferroni correction. Univariate logistic regression analysis was applied to find contributing factors for the presentation of each symptom. Multivariate logistic regression analysis was performed to identify independent contributing factors to each symptom; $p<0.05$ was considered significant.

\section{Results}

\section{Patient Demographics}

Demographic data of the 53 patients are listed in Table 1. Forty-eight patients $(90.6 \%)$ were female. The mean patient age was $60 \pm 16.48$ years (range 9-93 years). All meningiomas but one were found in adults. WHO grade I accounted for $94.3 \%$ of all meningiomas (50 of 53). Only 3 meningiomas $(5.7 \%)$ were WHO grade II. There were no WHO grade III meningiomas in our series. The thoracic spine was the most affected area, where $64.2 \%$ (34 of 53) of the tumors were found. The CVJ (24.5\%) and subaxial cervical spine (C3-7, 11.3\%) followed. As to clinical symptoms, 32 of 53 patients (60.4\%) exhibited motor weakness and were further classified into groups with subjective weakness (26.4\%) and objective weakness (34\%). Sensory disturbance was seen in $49.1 \%$ of patients (26 of 53 patients). Either radicular pain (30.2\%, 16 of 53 patients) or axial pain (34\%, 18 of 53 patients) was seen in $64.2 \%$ of patients (34 of 53). Nine of 53 patients (17\%) had BBD. With regard to attachment of the tumor in the spinal canal, lateral attachment was most frequent (32.1\%), followed by ventrolateral (30.2\%) and dorsolateral (26.4\%) attachment. Pure ventral and dorsal attachment were relatively rare, with frequencies of $3.8 \%$ and $7.5 \%$, respectively.

\section{Frequency of Each Symptom Depending on Spinal Level of Meningioma and Tumor Attachment}

The frequency of motor weakness, sensory disturbance, and pain was uneven among the 3 spinal level groups. More precisely, motor weakness and sensory disturbance were significantly more common in patients with thoracic spine meningiomas than in those with meningiomas at other spinal levels ( $p<0.001$ and $p=0.013$, respectively). While pain was more commonly associated with CVJ meningiomas than with other spinal level meningiomas $(\mathrm{p}<$ $0.001)$, BBD was only seen in patients with thoracic spine meningiomas $(\mathrm{p}=0.05)$. The frequency of each symptom by tumor attachment did not differ significantly (Table 2 ).

\section{Is There Any Difference in Tumor Dimensions Between the Presence and Absence of Symptoms?}

Height, width, depth, and volume of the tumors were not significantly different irrespective of the presence or absence of each symptom. Occupation ratios and spinal cord flattening ratios were significantly larger in the presence of motor weakness and sensory disturbance than in the absence of those symptoms, while those ratios in the presence of pain were significantly smaller than in the absence of pain (all $\mathrm{p}<0.05$; see detailed $\mathrm{p}$ values in Table 3 ). 
TABLE 1. Overall patient demographics

\begin{tabular}{|c|c|}
\hline & Value \\
\hline No. of patients & 53 \\
\hline Male & $5(9.4)$ \\
\hline Female & $48(90.6)$ \\
\hline Mean age $\pm S D$, yrs & $60 \pm 16.48$ \\
\hline \multicolumn{2}{|l|}{ WHO grade } \\
\hline I & $50(94.3)$ \\
\hline II & $3(5.7)$ \\
\hline Atypical & 2 \\
\hline Clear cell & 1 \\
\hline \multicolumn{2}{|l|}{ Spinal level } \\
\hline CVJ & $13(24.5)$ \\
\hline C3-7 & $6(11.3)$ \\
\hline T1-12 & $34(64.2)$ \\
\hline \multicolumn{2}{|l|}{ Motor weakness } \\
\hline No weakness & $21(39.6)$ \\
\hline Any weakness & $32(60.4)$ \\
\hline Subjective & $14(26.4)$ \\
\hline Objective & $18(34.0)$ \\
\hline \multicolumn{2}{|l|}{ Sensory disturbance } \\
\hline None & $27(50.9)$ \\
\hline Any & $26(49.1)$ \\
\hline \multicolumn{2}{|l|}{ Pain } \\
\hline No pain & $26(49.1)$ \\
\hline Radicular pain & $16(30.2)$ \\
\hline Axial pain & $18(34.0)$ \\
\hline BBD & $9(17.0)$ \\
\hline \multicolumn{2}{|c|}{ Attachment of the tumor } \\
\hline Ventral & $2(3.8)$ \\
\hline Ventrolateral & $16(30.2)$ \\
\hline Lateral & $17(32.1)$ \\
\hline Dorsal & $4(7.5)$ \\
\hline Dorsolateral & $14(26.4)$ \\
\hline
\end{tabular}

Values represent the number of patients (\%) unless stated otherwise.

\section{Contributing Factors for the Presentation of Each Symptom}

Univariate logistic regression analysis was performed to find contributing factors for each symptom (Table 4). As a result, both motor weakness and sensory disturbance were significantly related to thoracic spine lesions $(\mathrm{p}<$ 0.001 and $p=0.016$, respectively), occupation ratio ( $p<$ 0.001 and $p=0.010$, respectively), and spinal cord flattening ratio $(p<0.001$ and $p=0.025$, respectively). As to pain, CVJ lesions $(p=0.006)$, occupancy ratio $(p<0.001)$, and spinal cord flattening ratio $(\mathrm{p}=0.001)$ were significant contributing factors. To identify independent factors that contributed to each symptom, we conducted multivariate logistic regression. Occupation ratio was an independent contributing factor for the presentation of motor weakness (OR 1.14, 95\% CI 1.01-1.29, $\mathrm{p}=0.035)$ and pain (OR $0.925,95 \%$ CI $0.861-0.994, \mathrm{p}=0.034)$.

\section{Threshold Value of Occupation Ratio to Cause Motor Weakness}

When the motor weakness group was further classified into subjective and objective weakness, the occupation ratio of the no-weakness group was significantly smaller than that of the subjective- and objective-weakness groups ( $p<0.001$ ), while no significant difference in occupation ratio was found between subjective and objective weakness (Fig. 3 left). Receiver operating characteristic curve analysis suggested that an occupation ratio with a value of $63.678 \%$ had the highest sensitivity and specificity for the presence of subjective motor weakness. We can therefore conclude that an occupation ratio of $63.678 \%$ is the threshold to cause motor weakness (Fig. 3 right).

\section{Discussion}

\section{Symptoms of Spinal Meningiomas}

In the present study, motor weakness and sensory disturbance were significantly more common in thoracic meningiomas, and pain was more common in CVJ meningiomas. The ranges of incidence for each symptom reported in the literature are as follows: motor weakness, $63.5 \%$ 92.5\%; coordination/balance disorder, $6.7 \%-93 \%$, sensory disturbance, $50 \%-100 \%$; localized or radicular pain, 20\%-83\%; and BBD, 1.0\%-50\%.,3,7,7,10,14,16,18,23,25 As listed above, the frequencies of each symptom are quite heterogeneous among the reports. For example, Gezen et al. reported localized or radicular pain as the most common symptom with a frequency of $83 \%$, while in the retrospective analysis of 194 spinal meningiomas by Hua et al., pain was the second least common symptom, with a frequency of only $26 \% .^{7,10}$ Probably because of this heterogeneity, the researchers paid less attention to the symptomatology of spinal meningiomas. To our knowledge, there have been only a few reports regarding the relationship of the size of spinal meningioma to the presenting symptoms..$^{1,3,22}$

\section{Degree of Spinal Cord Compression by Intradural Extramedullary Tumors and Its Relation to the Symptomatology}

The present study showed that the occupation ratio is an independent contributing factor to the presentation of motor weakness and pain. Ahn et al. retrospectively analyzed 11 surgical cases of intradural extramedullary tumors comprising 8 schwannomas, 2 meningiomas, and 1 extramedullary grown ependymoma. ${ }^{1}$ Their metrics of occupation ratio were not based on the cross-sectional areas of tumors and the spinal canal, like the present study. The occupation ratio was calculated based on the ratio of the diameter of the tumor and the spinal canal at the level of the most significant spinal cord compression. The mean percentage of the occupation ratio of the tumor in the spinal canal was $82.9 \%$. This occupation ratio was highly associated with visual analog scale scores and Nurick grades. ${ }^{1}$ Davies et al. retrospectively analyzed their series of 31 surgically treated spinal meningiomas to find the relationship between degree of spinal cord compression and patients' functional status. They evaluated the occupation ratio by the same metrics as in the present study. The average tumor occupation ratio from preoperative MR images 
TABLE 2. Frequency of each symptom by spinal level

\begin{tabular}{|c|c|c|c|c|c|c|c|c|}
\hline & \multicolumn{2}{|c|}{ Motor Weakness } & \multicolumn{2}{|c|}{ Sensory Disturbance } & \multicolumn{2}{|c|}{ Pain } & \multicolumn{2}{|c|}{ BBD } \\
\hline & Yes & No & Yes & No & Yes & No & Yes & No \\
\hline \multicolumn{9}{|c|}{ Spinal level of tumor } \\
\hline CVJ & 3 & 10 & 2 & 11 & 12 & 1 & 0 & 13 \\
\hline C3-7 & 1 & 5 & 3 & 3 & 4 & 2 & 0 & 6 \\
\hline $\mathrm{T} 1-12$ & 28 & 6 & 21 & 13 & 11 & 23 & 9 & 25 \\
\hline p value* & \multicolumn{2}{|c|}{$<0.001$} & \multicolumn{2}{|c|}{0.013} & \multicolumn{2}{|c|}{$<0.001$} & \multicolumn{2}{|c|}{0.05} \\
\hline \multicolumn{9}{|c|}{ Attachment of tumor } \\
\hline Ventral & 1 & 1 & 0 & 2 & 2 & 0 & 0 & 2 \\
\hline Ventrolateral & 8 & 8 & 7 & 9 & 9 & 7 & 3 & 13 \\
\hline Lateral & 10 & 7 & 9 & 8 & 10 & 7 & 1 & 16 \\
\hline Dorsal & 2 & 2 & 3 & 1 & 2 & 2 & 1 & 3 \\
\hline Dorsolateral & 11 & 3 & 7 & 7 & 4 & 10 & 4 & 10 \\
\hline p value* & \multicolumn{2}{|c|}{0.52} & \multicolumn{2}{|c|}{0.627} & \multicolumn{2}{|c|}{0.282} & \multicolumn{2}{|c|}{0.43} \\
\hline
\end{tabular}

was $72 \%$. In contrast to the study by Ahn et al., no obvious relationship was found between occupation ratio and preor postoperative Nurick grade. ${ }^{3}$ In their retrospective analysis of 88 patients with spinal meningiomas, Schwake et al. found that tumor volume was not correlated to clinical symptoms such as sensory, motor deficit, radicular pain, or incontinence. ${ }^{22}$ No correlation was found between tumor volume and McCormick score. They found that tumor volume only correlated with the presence of low-back pain. The weak point of this study was that they did not take the size of the corresponding spinal canal into consideration. As shown in Table 3, there were no significant differences in the height, width, depth, and volume of the tumors irrespective of the presence or absence of each symptom, while occupation ratios showed significant differences in the presence of motor weakness, sensory disturbance, and pain. These results imply that the emergence of neurological symptoms depends more on the size of the tumor relative to the spinal canal rather than the actual size of the tumor. Finally, multivariate analysis in the present study disclosed that occupation ratio was the sole independent contributing factor for the presence of motor weakness and pain. We believe that the occupation ratio is useful to study the effect of intraspinal mass lesions on the spinal cord.

\section{Degree of Spinal Cord Compression by Lesions Other Than Spinal Cord Tumors and Its Relation to Symptomatology}

Quantification of the degree of spinal cord compression and its influence on clinical symptoms has also been studied in spinal diseases other than spinal cord tumors. Ossification of the posterior longitudinal ligament (OPLL) is a well-known cause of compressive myelopathy in the cervical spine. Matsunaga et al. prospectively studied patients with asymptomatic cervical OPLL with a mean follow-up duration of 19.6 years. ${ }^{17}$ They evaluated the degree of spinal cord compression on lateral cervical radiographs by dividing anteroposterior thickness of the ossified ligament by anteroposterior diameter of the corresponding spinal canal. All patients with an occupation ratio greater than $60 \%$ developed cervical myelopathy at some point in the follow-up period. Kameyama et al. histologically analyzed spinal cords that were obtained from 9 autopsy cases of patients who had known cervical OPLL. ${ }^{2}$ They found that irreversible pathological changes were associated with a triangular-shaped deformity of the spinal cord and were also associated with occupation ratios exceeding $40 \%$. Tung et al. evaluated the thickness of spinal epidural abscesses to find a correlation between degree of spinal cord compression and postoperative symptoms. ${ }^{28}$ The occupation ratio was measured based on the anteroposterior diameter of the spinal canal and abscess. Spinal epidural abscesses with an occupation ratio greater than $50 \%$ were associated with persistent weakness, back pain, and incomplete clinical recovery. As shown above, the threshold of spinal cord compression to present with neurological symptoms and its radiological parameters have been a matter of interest to many researchers. ${ }^{24}$ These studies suggested that an occupation ratio of $40 \%-60 \%$, measured from the anteroposterior diameter of the lesion and the spinal canal, seems to be a critical point of spinal cord compression to manifest as significant neurological symptoms. The present study suggests that an occupation ratio of $63.678 \%$ is the threshold to cause motor weakness. Unfortunately, we cannot simply compare the results of the present study with those of prior ones because of the difference in metrics for the occupation ratio. In the process of study planning, we thought that an occupation ratio based on anteroposterior diameter of the lesion and spinal canal was inappropriate for spinal meningiomas because spinal cord compression by the tumor is not always anteroposterior, like OPLL. The direction of spinal cord compression by spinal meningiomas varies depending on tumor attachment. Therefore, we decided to evaluate the occupation ratio based on the cross-sectional area of the tumor and the spinal canal. We hope that further studies 


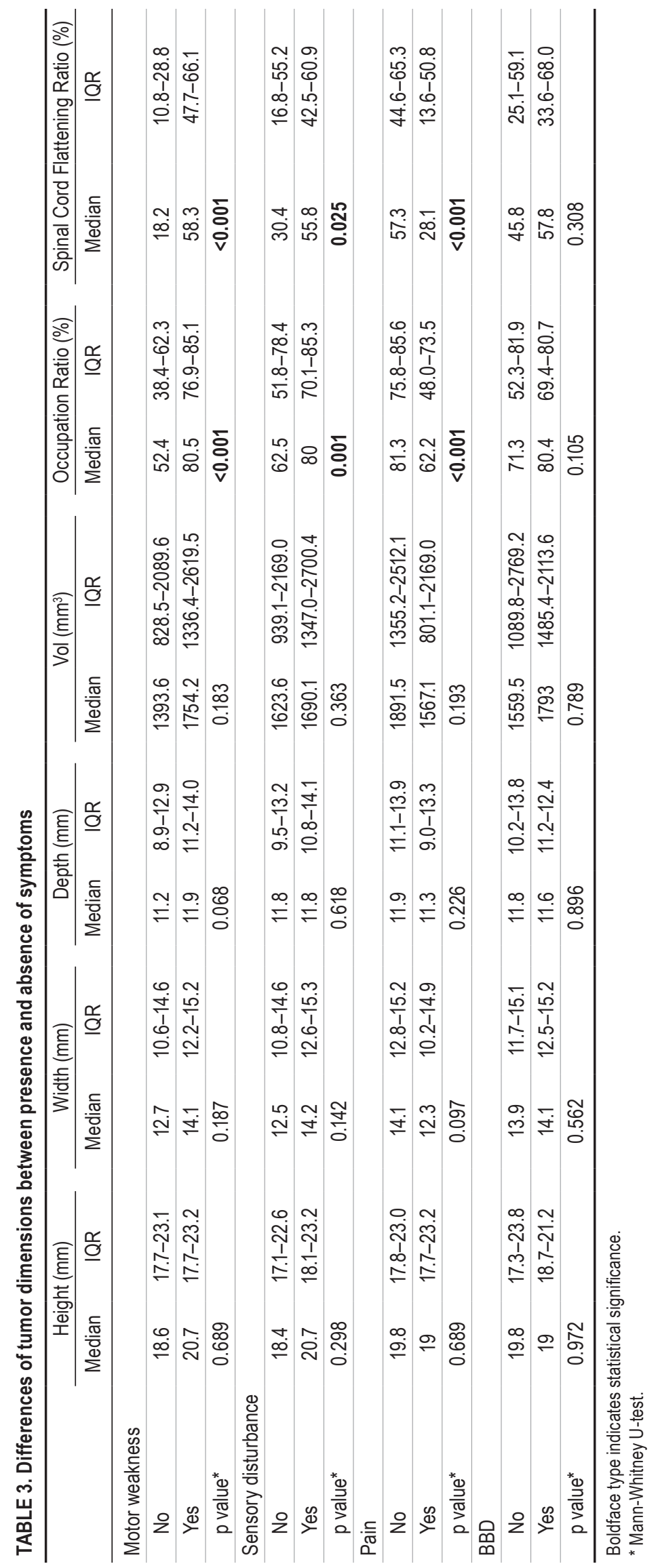


TABLE 4. Univariate and multivariate logistic regression analyses for each symptom

\begin{tabular}{|c|c|c|c|c|c|}
\hline & $\begin{array}{l}\text { Possible Contributing } \\
\text { Factor }\end{array}$ & OR & $\begin{array}{l}\text { Lower } \\
95 \% \mathrm{CL}\end{array}$ & $\begin{array}{l}\text { Upper } \\
95 \% \text { CL }\end{array}$ & $\begin{array}{c}p \\
\text { Value }\end{array}$ \\
\hline \multicolumn{6}{|c|}{ Univariate logistic regression analysis } \\
\hline \multirow{5}{*}{ Motor weakness } & Age & 1.02 & 0.982 & 1.05 & 0.357 \\
\hline & Male sex & 2.86 & 0.297 & 27.5 & 0.364 \\
\hline & Thoracic spine lesion & 17.5 & 4.26 & 71.8 & $<0.001$ \\
\hline & Occupation ratio & 1.2 & 1.09 & 1.33 & $<0.001$ \\
\hline & Spinal cord flattening ratio & 1.13 & 1.06 & 1.19 & $<0.001$ \\
\hline \multirow{5}{*}{ Sensory disturbance } & Age & 0.994 & 0.961 & 1.03 & 0.708 \\
\hline & Male sex & 1.63 & 0.25 & 10.6 & 0.61 \\
\hline & Thoracic spine lesion & 4.52 & 1.32 & 15.5 & 0.016 \\
\hline & Occupation ratio & 1.05 & 1.01 & 1.09 & 0.010 \\
\hline & Spinal cord flattening ratio & 1.03 & 1.00 & 1.06 & 0.025 \\
\hline \multirow{5}{*}{ Pain } & Age & 0.991 & 0.959 & 1.02 & 0.606 \\
\hline & Male sex & 0.613 & 0.093 & 4.01 & 0.61 \\
\hline & CVJ lesion & 20 & 2.36 & 170 & 0.006 \\
\hline & Occupation ratio & 0.903 & 0.851 & 0.958 & $<0.001$ \\
\hline & Spinal cord flattening ratio & 0.947 & 0.916 & 0.978 & 0.001 \\
\hline \multicolumn{6}{|c|}{ Multivariate logistic regression analysis } \\
\hline \multirow{3}{*}{ Motor weakness } & Thoracic spine lesion & 0.835 & 0.0587 & 11.9 & 0.894 \\
\hline & Occupation ratio & 1.14 & 1.01 & 1.29 & 0.035 \\
\hline & Spinal cord flattening ratio & 1.06 & 0.993 & 1.14 & 0.078 \\
\hline \multirow{3}{*}{ Sensory disturbance } & Thoracic spine lesion & 1.74 & 0.327 & 9.11 & 0.521 \\
\hline & Occupation ratio & 1.04 & 0.979 & 1.10 & 0.203 \\
\hline & Spinal cord flattening ratio & 1.00 & 0.960 & 1.04 & 0.956 \\
\hline \multirow{3}{*}{ Pain } & CVJ lesion & 7.52 & 0.746 & 75.8 & 0.087 \\
\hline & Occupation ratio & 0.925 & 0.861 & 0.994 & 0.034 \\
\hline & Spinal cord flattening ratio & 0.997 & 0.952 & 1.050 & 0.912 \\
\hline
\end{tabular}

will standardize the method of quantification of spinal cord compression and will help elucidate the pathophysiology of compressive myelopathy. ${ }^{27}$

\section{Relationship Between Occupation Ratio and Pain}

As shown in Table 4, the odds ratio of the occupation ratio for pain symptoms was 0.925 . An odds ratio of $<1$ means that the larger the occupation ratio, the less likely the tumor will cause pain. This is somewhat contradictory given the general idea of tumors becoming symptomatic with growth. This contradiction can probably be explained by the following results. Table 2 shows that pain symptoms were more common in patients with CVJ meningiomas than with thoracic spine meningiomas. When we focused on patients who presented exclusively with pain $(n=18)$, we found that 13 of 18 meningiomas (72\%) arose in the cervical spine. This implies that meningiomas in the cervical spine are likely to present with pain. As to tumor size and the degree of the spinal cord compression, occupation ratios and spinal cord flattening ratios for meningiomas in the CVJ and subaxial cervical spine (C3-7) were significantly smaller than those ratios for meningiomas in the thoracic spine ( $p<0.001$; Fig. 4). When we put all these results together, it might be concluded that relatively small spinal meningiomas in the cervical spine are likely to manifest as pain symptoms rather than motor weakness. Assuming that the neck and arms are more sensitive than the thoracic area to radicular-type pain, meningiomas arising in the cervical spine might take the patient to the hospital before the tumor grows large enough to cause motor weakness.

\section{Study Limitations}

There are some limitations in this study. First, this study did not take mobility of the spine into consideration. The development of compressive myelopathy mainly derives from two physical factors: static and dynamic compression. Under the existence of some space-occupying lesions in the spinal canal, the degree of compression and the magnitude of strain force on the spinal cord are known to change by physiological motion of the neck, especially in the middle cervical spine. ${ }^{11,20,26}$ The thoracic spine, which is surrounded by the rib cage, is more rigid than the cervical spine. The difference in symptoms between cervical 

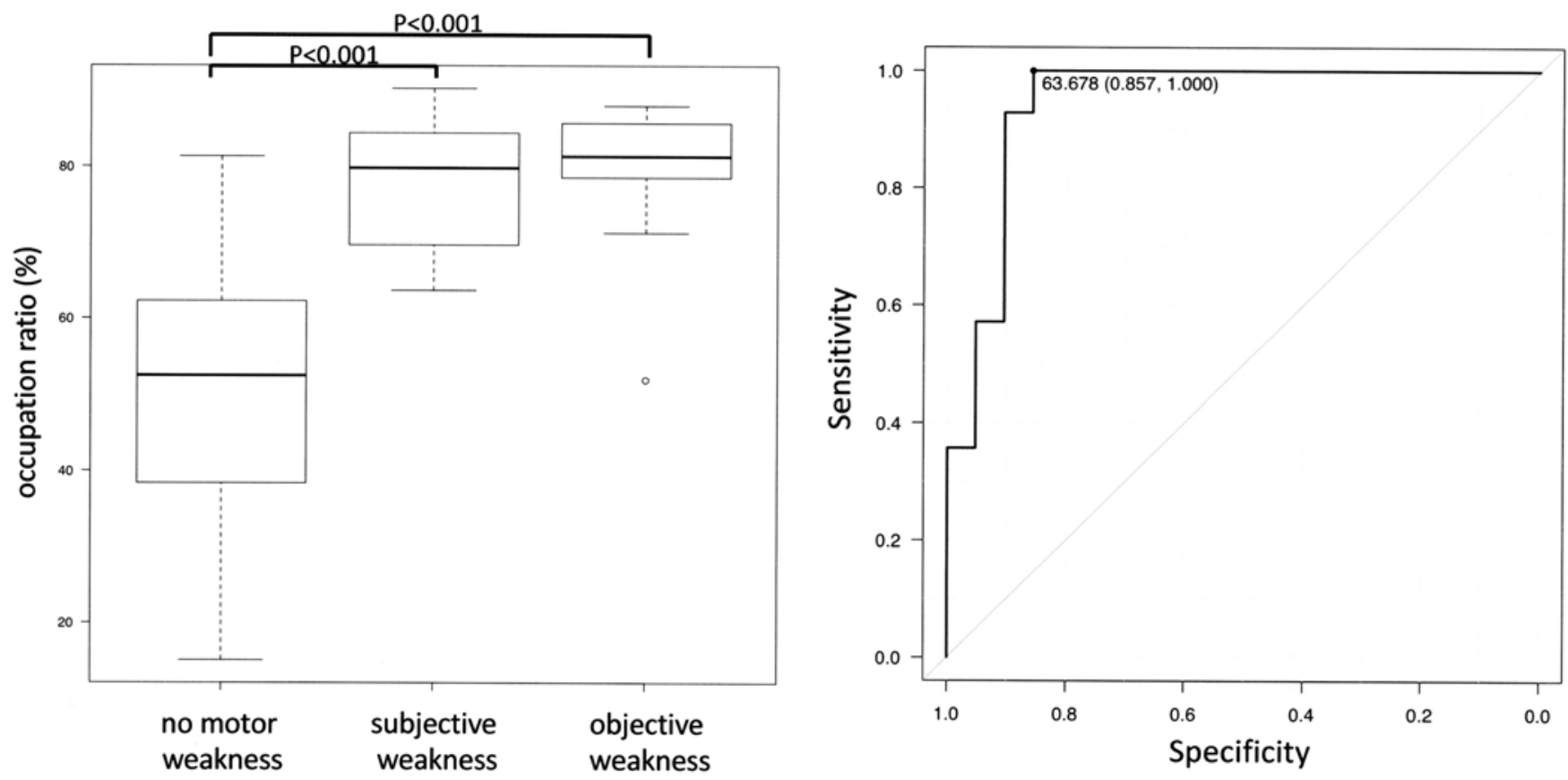

FIG. 3. Left: Occupation ratios in the no-weakness group were significantly smaller than those of groups with subjective and objective weakness $(p<0.01)$. Kruskal-Wallis test for primary comparison and Mann-Whitney U-test for pairwise comparison. Right: Receiver operating characteristic curve analysis indicating that an occupation ratio of $63.678 \%$ had the highest sensitivity and specificity for the presence of motor weakness.
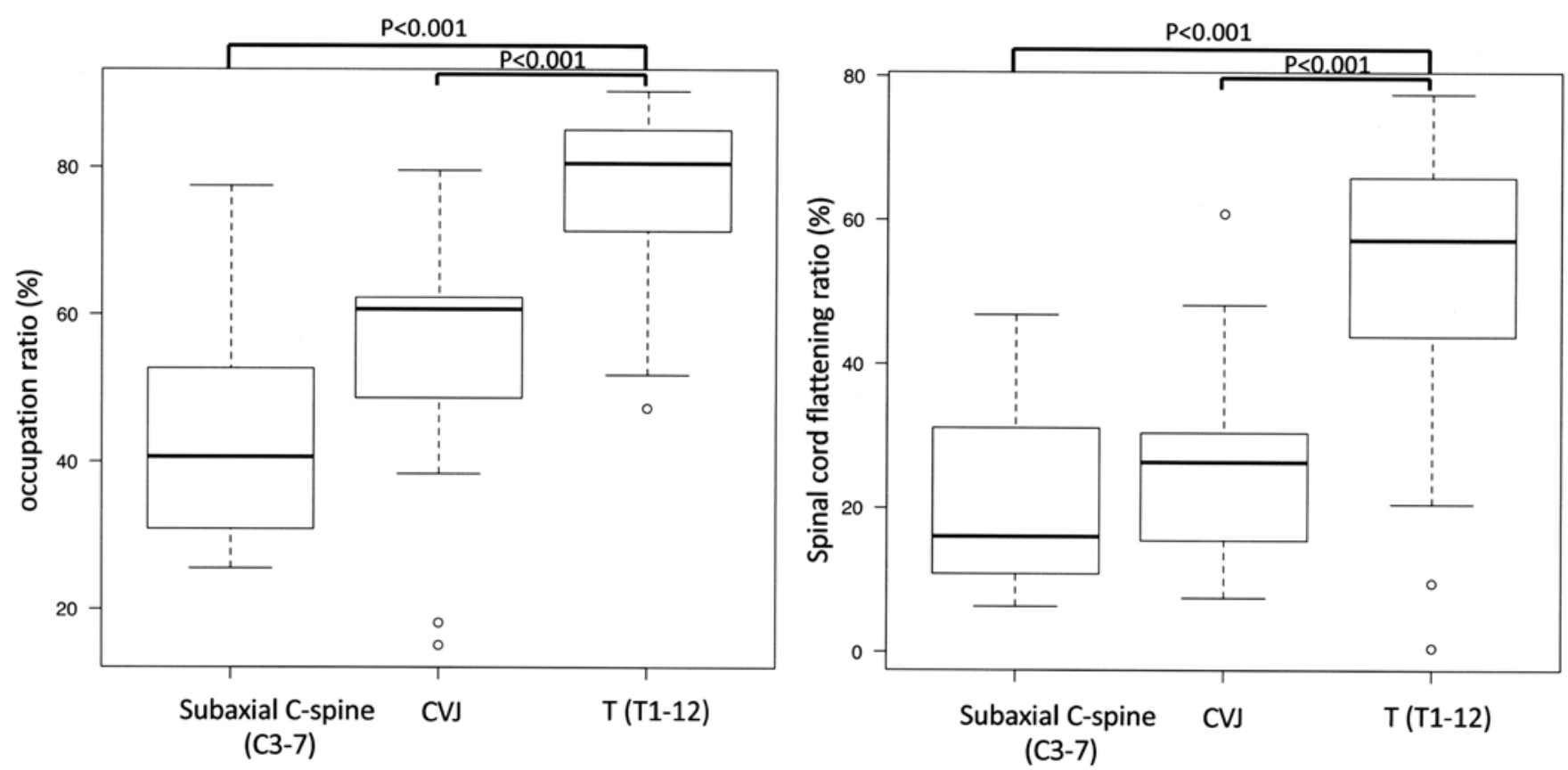

FIG. 4. Left: Occupation ratios of meningiomas in the CVJ and subaxial spine (C3-7) were significantly smaller than those of meningiomas in the thoracic spine (T1-12) $(p<0.001)$. Right: Spinal cord flattening ratios in the CVJ and C3-7 were significantly smaller than those of meningiomas in the thoracic spine $(p<0.001)$. Kruskal-Wallis test for primary comparison and Mann-Whitney U-test for pairwise comparison. 
and thoracic meningiomas might be partially explained by the difference in mobility of the affected spine. Second, we cannot exclude the possibility that hand clumsiness and walking difficulty, which were classified as subjective motor weakness in the study, might derive from disorders of proprioception and coordination. It is possible that our classification of pain might not have been completely accurate. Spinal meningiomas might have caused other types of pain, such as funicular pain. Considering the patients' mean age of $60 \pm 16.48$ years, mechanical pain deriving from cervical spondylosis in the background might have affected the intensity of the pain. However, further evaluation of symptoms in the electronic medical records was not possible because of the retrospective nature of this study. Lastly, the impact of this study on the management of spinal meningiomas might be small. However, we believe that this study will contribute to the elucidation of the pathophysiology of spinal meningiomas and compressive myelopathy.

\section{Conclusions}

The present study shows differences in the clinical presentation of spinal meningiomas by spinal level and occupation ratio. Motor weakness and sensory disturbance were more commonly seen in thoracic spine meningiomas. Pain was more common in meningiomas at the CVJ. Tumor growth in the cervical spine might cause pain symptoms before causing motor weakness. An occupation ratio of about $64 \%$ could be utilized as the threshold value of tumor growth to cause motor weakness. The relationship between the tumor and its symptomatology should be discussed not only with regard to actual size but also with regard to size of the tumor relative to the surrounding spinal canal.

\section{References}

1. Ahn DK, Park HS, Choi DJ, Kim KS, Kim TW, Park SY: The surgical treatment for spinal intradural extramedullary tumors. Clin Orthop Surg 1:165-172, 2009

2. Beall DP, Googe DJ, Emery RL, Thompson DB, Campbell SE, Ly JQ, et al: Extramedullary intradural spinal tumors: a pictorial review. Curr Probl Diagn Radiol 36:185-198, 2007

3. Davies S, Gregson B, Mitchell P: Spinal meningioma: relationship between degree of cord compression and outcome. Br J Neurosurg 31:209-211, 2017

4. Duong LM, McCarthy BJ, McLendon RE, Dolecek TA, Kruchko C, Douglas LL, et al: Descriptive epidemiology of malignant and nonmalignant primary spinal cord, spinal meninges, and cauda equina tumors, United States, 2004-2007. Cancer 118:4220-4227, 2012

5. Engelhard HH, Villano JL, Porter KR, Stewart AK, Barua M, Barker FG, et al: Clinical presentation, histology, and treatment in 430 patients with primary tumors of the spinal cord, spinal meninges, or cauda equina. J Neurosurg Spine 13:67-77, 2010

6. Faustino-Rocha A, Oliveira PA, Pinho-Oliveira J, TeixeiraGuedes C, Soares-Maia R, da Costa RG, et al: Estimation of rat mammary tumor volume using caliper and ultrasonography measurements. Lab Anim (NY) 42:217-224, 2013

7. Gezen F, Kahraman S, Canakci Z, Bedük A: Review of 36 cases of spinal cord meningioma. Spine (Phila Pa 1976) 25:727-731, 2000
8. Gilard V, Goia A, Ferracci FX, Marguet F, Magne N, Langlois $\mathrm{O}$, et al: Spinal meningioma and factors predictive of post-operative deterioration. J Neurooncol 140:49-54, 2018

9. Gottfried ON, Gluf W, Quinones-Hinojosa A, Kan P, Schmidt $\mathrm{MH}$ : Spinal meningiomas: surgical management and outcome. Neurosurg Focus 14(6):e2, 2003

10. Hua L, Zhu H, Deng J, Tian M, Jiang X, Tang H, et al: Clinical and prognostic features of spinal meningioma: a thorough analysis from a single neurosurgical center. J Neurooncol 140:639-647, 2018

11. Joaquim AF, Baum GR, Tan LA, Riew KD: Dynamic cord compression causing cervical myelopathy. Neurospine 16:448-453, 2019

12. Kameyama T, Hashizume Y, Ando T, Takahashi A, Yanagi T, Mizuno J: Spinal cord morphology and pathology in ossification of the posterior longitudinal ligament. Brain 118:263278, 1995

13. Kanda Y: Investigation of the freely available easy-to-use software 'EZR' for medical statistics. Bone Marrow Transplant 48:452-458, 2013

14. Klekamp J, Samii M: Surgical results for spinal meningiomas. Surg Neurol 52:552-562, 1999

15. Kshettry VR, Hsieh JK, Ostrom QT, Kruchko C, Benzel EC, Barnholtz-Sloan JS: Descriptive epidemiology of spinal meningiomas in the United States. Spine (Phila Pa 1976) 40:E886-E889, 2015

16. Levy WJ Jr, Bay J, Dohn D: Spinal cord meningioma. J Neurosurg 57:804-812, 1982

17. Matsunaga S, Sakou T, Hayashi K, Ishidou Y, Hirotsu M, Komiya S: Trauma-induced myelopathy in patients with ossification of the posterior longitudinal ligament. J Neurosurg 97 (2 Suppl):172-175, 2002

18. Riad H, Knafo S, Segnarbieux F, Lonjon N: Spinal meningiomas: surgical outcome and literature review. Neurochirurgie 59:30-34, 2013

19. Saraceni C, Harrop JS: Spinal meningioma: chronicles of contemporary neurosurgical diagnosis and management. Clin Neurol Neurosurg 111:221-226, 2009

20. Sayit E, Aghdasi B, Daubs MD, Wang JC: The occupancy of the components in the cervical spine and their changes with extension and flexion. Global Spine J 5:396-405, 2015

21. Schellinger KA, Propp JM, Villano JL, McCarthy BJ: Descriptive epidemiology of primary spinal cord tumors. J Neurooncol 87:173-179, 2008

22. Schwake M, Adeli A, Sporns P, Ewelt C, Schmitz T, Sicking J, et al: Spinal meningiomas-risks and potential of an increasing age at the time of surgery. J Clin Neurosci 57:8692,2018

23. Setzer M, Vatter H, Marquardt G, Seifert V, Vrionis FD: Management of spinal meningiomas: surgical results and a review of the literature. Neurosurg Focus 23(4):E14, 2007

24. Shimokawa N, Sato H, Matsumoto H, Takami T: Review of radiological parameters, imaging characteristics, and their effect on optimal treatment approaches and surgical outcomes for cervical ossification of the posterior longitudinal ligament. Neurospine 16:506-516, 2019

25. Solero CL, Fornari M, Giombini S, Lasio G, Oliveri G, Cimino C, et al: Spinal meningiomas: review of 174 operated cases. Neurosurgery 25:153-160, 1989

26. Stoner KE, Abode-Iyamah KO, Magnotta VA, Howard MA, Grosland NM: Measurement of in vivo spinal cord displacement and strain fields of healthy and myelopathic cervical spinal cord. J Neurosurg Spine 31:53-59, 2019

27. Tempest-Mitchell J, Hilton B, Davies BM, Nouri A, Hutchinson PJ, Scoffings DJ, et al: A comparison of radiological descriptions of spinal cord compression with quantitative measures, and their role in non-specialist clinical management. PLoS One 14:e0219380, 2019

28. Tung GA, Yim JW, Mermel LA, Philip L, Rogg JM: Spinal 
epidural abscess: correlation between MRI findings and outcome. Neuroradiology 41:904-909, 1999

29. Westwick HJ, Shamji MF: Effects of sex on the incidence and prognosis of spinal meningiomas: a Surveillance, Epidemiology, and End Results study. J Neurosurg Spine 23:368-373, 2015

\section{Disclosures}

The authors report no conflict of interest concerning the materials or methods used in this study or the findings specified in this paper.

\section{Author Contributions}

Conception and design: Yamaguchi. Acquisition of data: Yamaguchi. Analysis and interpretation of data: Yamaguchi. Drafting the article: Yamaguchi. Critically revising the article: Menezes, Shimizu. Reviewed submitted version of manuscript: Woodroffe, Helland, Hitchon, Howard. Statistical analysis: Yamaguchi, Shimizu. Study supervision: Hitchon, Howard.

\section{Correspondence}

Satoshi Yamaguchi: University of Iowa Hospitals and Clinics, Iowa City, IA. satoshi-yamaguchi@uiowa.edu. 